\title{
Comunicação, humanidades e humanização: a educação técnica, ética, estética e emocional do estudante e do profissional de saúde
}

Mario Alfredo De Marco ${ }^{1}$ Mariella Vargas Degiovani² Miriam Sansoni Torossian ${ }^{3}$ Rudolf Wechsler ${ }^{4}$ Silvia Mara Herbelha Joppert ${ }^{5}$ Ana Cecília Lucchese ${ }^{6}$

\section{Introdução}

\section{Que é isso, a humanização?}

Palavra de ordem no campo da saúde, o conceito de humanização, ameaçado pelos perigos do modismo e da banalização, necessita arejamento e discussão crítica.

Desgaste e incompreensão ficam patentes nas observações quando da discussão do tema com estudantes e profissionais de saúde. De um lado, há os que tendem à banalização, reduzindo o conceito a algumas noções básicas de cordialidade e educação: "Claro que é importante ser humano com os pacientes!"; "Tem que saber o nome do paciente"; "Tem que ser educado e atencioso", e por aí vai. De outro, há os que se revoltam: "Humanizar o quê? Por acaso já não somos humanos?"

Contrariamente ao apontado nestas declarações, expressão do senso comum, nem nascemos humanizados nem o processo de humanização pode ser considerado tarefa simples. Ele implica a construção do sujeito graças à transmissão de milênios de evolução cultural. Assim como os cromossomos dos pais transmitem características acumuladas ao longo de milhões de anos de evolução, o que a cultura alcançou em sua evolução é transmitido através da relação e comunicação.

\section{Comunicação, padrões vinculares e constituição do sujeito}

O movimento ontológico-constituidor do humano se abre tanto para a possibilidade de enraizamento quanto alienação (Gomes, Schraiber, 2011), e o processo de constituição do sujeito é essencialmente relacional. Isto é, comunicação e relação, atualizadas em padrões vinculares, determinam extensão e qualidade da construção do mundo psíquico. Vamos ilustrar este processo de internalização das relações e construção de padrões vinculares através de duas variantes de uma cena de interação entre mãe e bebê: o bebê chora e a mãe se prontifica a assisti-lo, tentando decifrar a qualidade do choro e identificar a perturbação/demanda. Começa a confortá-lo, segurando-o no colo e conversando

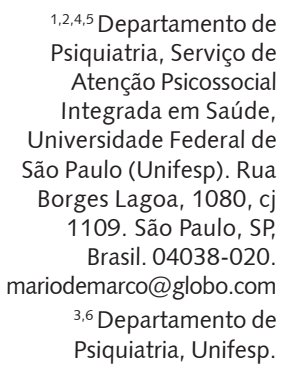


com ele naquele dialeto típico ("manhês"), com suas sonoridades peculiares. Pode decifrar imediatamente e atender a necessidade da criança ou, por tentativa e erro, sem muito desespero, buscar soluções, até conseguir confortar a criança que, então, se acalma e interrompe o choro.

Numa variante, a mãe, frente ao choro do bebê, entra em desespero e, tomada pela ansiedade, tenta se desembaraçar daquela perturbação oferecendo, sofregamente, opções para atender a demanda da criança. A ansiedade da mãe potencializa a ansiedade da criança, gerando retroalimentação recíproca. Finalmente, após tempo variável de vivência intensamente aflitiva, sobrevém a interrupção do choro da criança.

Embora com desfecho semelhante, da perspectiva da experiência e construção dos padrões vinculares, a diferença é crucial. No caso do primeiro bebê, a experiência produzirá os seguintes registros internos (introjeções): existe um "objeto" ameaçador para o qual, evidentemente, o bebê não tem nome, mas existe um "objeto" com capacidade de permanecer em contato com este estado e oferecer continência, conforto e alívio da turbulência. Este padrão relacional vai gradativamente sendo incorporado pela criança, permitindo que ela possa evoluir emocionalmente, discriminando e nomeando progressivamente as demandas associadas às turbulências vivenciadas (dor, fome, sede etc.) e as diferentes nuances emocionais (ódio, tristeza, amor etc.).

No caso do segundo bebê, a situação é completamente diferente. Ele incorpora que não existe continência para seu estado de terror-sem-nome (Bion, 1991). Após repetição reiterada dessa experiência, a tendência, tendo em vista sobreviver, será excluir essas emoções da vida mental, que, consequentemente, fica empobrecida. Essas emoções permanecerão em sua configuração primitiva, em estado latente, podendo manifestar-se de forma sintomática ao longo da vida.

Os conceitos de continente, contido e rêverie, formulados pelo psicanalista Wilfred Bion (1991), são úteis para compreender esta capacidade mental materna em participar do processo que contribui para a psiquização das vivências da criança. A rêverie materna desempenha, para o bebê, a função de modificar e transformar suas ansiedades e tensões, permitindo que mãe e criança integrem o processo que será protótipo do pensamento da criança e que continuará a se desenvolver através da vida. A rêverie é uma capacidade mental que Bion descreveu, inicialmente, como atributo importante da mãe (rêverie materna), cuja situação paradigmática é a capacidade de a mãe tolerar a identificação projetiva de pânico e terror sem nome, que o bebê efetua, contendo e transformando estas emoções, de forma que a criança sinta que recebe de volta sua temida personalidade, numa forma mais tolerável.

Esta capacidade materna é estendida por Bion para a capacidade do analista em seu trabalho e ampliada para as situações da vida em geral; alcançar e manter esse estado é útil em muitas outras tarefas além da análise; é essencial para a eficiência mental apropriada para uma tarefa, seja qual for a tarefa (Bion, 1992).

Observações, a partir desta perspectiva, permitem distinguir situações em que o crescimento psíquico ocorre desligado de sua base emocional e, outras, em que vem acompanhado de evolução emocional.

Como consequência, teremos uma humanização ancorada numa base real e uma humanização estereotipada. Na humanização "real", existe contato e evolução através da transformação da base psíquica do ser. Na humanização estereotipada, existe desligamento, que favorece a incorporação de padrões estereotipados de conduta. Padrões ditados (pré-moldados) e não construídos promovem estruturação da personalidade que tem recebido diversas denominações, entre as quais: "falso Self", proposta por Winniccott (2000), ou identificação com a "persona" proposta por Jung (1987).

O tema é relevante, pois as observações apontam que, na atualidade, esta condição é endêmica. Se, no tempo das origens da psicanálise, a histeria ocupava posição central, hoje, é absolutamente periférica. No centro do palco, temos, hoje: distúrbios de identidade nomeados como "falso Self", personalidades "como se", identificação com a persona, pseudomaturidade, associados com patologias de gratificação peremptória, todas denominações procurando circunscrever estruturação de identidade superficial, inautêntica, porque desligada de sua base real. 


\section{Natureza e cultura}

O ser humano é uma das criaturas que, ao nascimento, apresenta maior imaturidade e, como corolário, maior plasticidade, sendo seu desenvolvimento amplamente condicionado pelos estímulos aos quais é exposto. Esta característica o faz amplamente adaptável, permitindo-lhe aventurar-se pelas diferentes regiões do planeta.

Graças à imaturidade, veio somar-se, à evolução condicionada pela herança genética, a evolução proporcionada pela herança cultural.

Se uma criança nasce, hoje, com características genéticas muito próximas a outra nascida há cinco mil anos, em poucos anos a herança cultural produzirá enorme diferenciação, na medida em que aquisições humanizadoras, construídas culturalmente, lhe serão transmitidas.

\section{Entre emoções e ética}

As evoluções culturais transmitidas podem ser divididas em quatro categorias básicas: técnicas, éticas, estéticas e emocionais.

A educação técnica mobiliza menos situações conflitivas, pois não envolve diretamente questões de valores.

A relação entre educação ética e emocional tem sido objeto de reflexões. Segundo Kesselring (2006), por muito tempo as emoções foram negligenciadas pela ética. Ele atribui esta negligência à influência, entre outras, do pensamento de Kant, que postulava que uma ação moralmente boa é racional. Na perspectiva kantiana, a qualidade ética advém do fato de que esta ação deve ser realizada, em contraposição a atos executados para satisfazer prazeres associados a inclinações e que, portanto, não possuem qualidade ética. Em contraposição, o que tem sido demonstrado sem maiores dificuldades é o papel que sentimentos morais e empatia desempenham no desenvolvimento da conduta moral.

Esta contraposição entre uma ética ditada racionalmente e outra ancorada em estruturas inatas se insere numa discussão mais ampla entre duas vertentes de respostas à construção da dimensão moral da humanidade (Hoffmann, 2000).

De um lado, uma visão de "pecado original" assume que as pessoas nascem egoístas e adquirem um senso moral através da socialização, que controla o egoísmo e que tem paralelismo nos primeiros freudianos e nas teorias de aprendizado social, que sublinham a importância para o desenvolvimento moral da punição e recompensa pelos pais, especialmente dando e retirando afeto.

Diametralmente oposta é a doutrina da pureza inata, associada, particularmente, a Rousseau, que via a criança como tendo uma bondade inata (sensível aos outros) sujeita à corrupção pela sociedade. Esta postura tem paralelismo com a teoria de Piaget, não no sentido de que as crianças sejam inatamente puras, mas que o contato com os adultos produz um respeito heterônomo por papéis e autoridade que interfere com o desenvolvimento moral. A semelhança com a "pureza inata" é que, nesta visão, é a interação livre e natural de crianças pré-morais que produz desenvolvimento moral, ao passo que a interação com adultos (socializados) previne este desenvolvimento (De Marco et al., 2012).

Uma discussão importante é quanto cada uma destas visões corresponde a uma dimensão da construção do desenvolvimento moral.

\section{As duas dimensões da moralidade}

A formulação de uma base inata para a construção do desenvolvimento moral tem sido reforçada pelas descobertas da biologia, antropologia e neurociência.

A evolução destes conhecimentos coloca em questão, inclusive, a concepção de muitos filósofos e antropólogos quanto a considerar que, entre os atributos que tornam o ser humano único, está a capacidade de agir moralmente.

Repetidas e consistentes observações demonstram a existência de comportamentos sociais em animais, associados a empatia e preocupação com o sofrimento dos outros: quando um chimpanzé entra em sofrimento por perder uma luta, cair de uma árvore ou outro evento estressante, os outros 
prontamente se disponibilizam para proporcionar conforto e reasseguramento. Eles o abraçam, beijam e afagam, tentando acalmá-lo.

Estes comportamentos, considerados componentes da evolução da inteligência social, não estão restritos aos primatas, sendo observados em elefantes, cetáceos (golfinhos e baleias) e, mesmo, em pássaros (uma espécie da família dos corvos).

Os humanos podem ser únicos no grau de aplicação da ética e moralidade para a tomada racional de decisões, mas, estas observações que demonstram a presença da empatia em animais fornecem importantes pistas quanto a um substrato neurológico destas habilidades (Hunter, 2010).

Do campo das neurociências, sistemas cerebrais envolvidos na empatia e na inteligência social têm sido identificados, indicando que nosso complexo mundo social, culturalmente variado e governado por códigos morais escritos e tácitos, que estimulam comportamentos de solidariedade mútua, está ancorado num sistema neural que tem como propriedade central permitir identificação e compreensão das intenções e ações do outro. Denominado sistema neurônios-espelho, parece "espelhar" as ações realizadas, codificando uma correspondência funcional entre ação motora e percepção sensorial desta ação. Evidências de observações e técnicas de neuroimagem indicam que este sistema forma parte da atividade neural que participa do processo de mobilização de preocupação empática, a capacidade de sentir e compreender o estado emocional do outro. Esta base biológica correlacionada à capacidade empática constitui, segundo a visão que estas pesquisas vêm sugerindo, o substrato para o desenvolvimento da nossa sofisticada evolução social e da base moral que a governa (Molnar-Szakacs, 2011).

A partir desta perspectiva, podemos avançar a concepção de que, na evolução social, regras de moralidade apoiadas nesta base são elaboradas, determinando a construção de papéis sociais, expectativas e sanções a que o sujeito estará submetido.

A construção do sujeito estará, portanto, apoiada em dois níveis de socialização: de um lado, conquistas e construções sociais transmitidas para ativação e evolução das capacidades naturais, e, de outro, imposição pura e simples das expectativas sociais.

A imposição é menos trabalhosa, de forma que o perigo de um desvio para esta tendência estará sempre rondando o processo de humanização.

Quando isto ocorre, o resultado é uma personalidade estruturada com base nos papéis e expectativas sociais, mas desligada de uma base profunda que permitiria ao indivíduo construir condutas morais a partir da vivência e elaboração dos conflitos entre emoções "egoístas" e emoções socialmente orientadas. A partir do exposto, podemos falar de uma humanização "verdadeira" e uma humanização "implantada". Na humanização "verdadeira", os preceitos morais serão incorporados através de uma matriz vivencial, e não como submissão a uma autoridade.

Uma leitura destas condições pode ser realizada através de conceituações provenientes das observações psicanalíticas. Jung, conforme já mencionamos, denomina persona a estes papéis desempenhados pelo sujeito, referindo-se este termo latino à máscara utilizada pelo ator na antiguidade. $O$ termo caracteriza nossa disposição inata para a adaptação à coletividade mediante o desempenho de papéis no palco do mundo (Whitmont, 1995). Esta adaptação representa perigo quando a personalidade total se identifica com os papéis, construindo uma identidade apoiada nos mesmos, resultando no que Jung denomina identificação com a persona, construção de um sujeito desligado de sua autenticidade. Da perspectiva da interação, o resultado será um sujeito com uma humanização superficial traduzida em polidez e simulacro de interesse e respeito pelo outro.

As consequências da identificação com a persona são importantes do ponto de vista pessoal e social, pois, os aspectos socialmente indesejáveis excluídos encontrarão outras formas de expressão, como, por exemplo, o fenômeno do bode expiatório, no qual esses aspectos são projetados nos outros (os vizinhos, outros povos, etnias etc.).

Outro autor que formulou importante contribuição para o tema é Donald Winnicott (2000), através do conceito de concern (traduzido como preocupação). Para ele, a capacidade de se preocupar é inata e, se as condições forem favoráveis, os valores correspondentes serão criados a partir de vivência e maturação. Em condições desfavoráveis, teremos um desligamento da base profunda do ser e a construção de um falso self (De Marco et al., 2012). 


\section{Humanidades, humanização e medicina}

A partir da adesão ao modelo científico fundado na experimentação, a medicina construiu um modelo biomédico que propiciou impulso considerável na ampliação de conhecimentos e práticas. Nesta trajetória, contudo, por não se adaptarem ao modelo experimental, houve desconsideração pelos fenômenos psíquicos, que passaram a constituir um estorvo, uma intromissão indesejada (De Marco, 2003). O objetivo desta medicina tem sido a compreensão da fisiologia e patologia do corpo, como se estas dimensões fossem independentes das vivências e emoções. A formação nas escolas médicas tem seguido preferencialmente este modelo, isolando o físico para facilitar a compreensão dos fenômenos estudados, e desconsiderando as dimensões emocionais e vivenciais que constituem a base essencial do processo de evolução cultural e humanização, e que determinam sentido e qualidade de nossa existência, bem como interferem no processo saúde-doença.

\section{O resgate da dimensão psicossocial e o modelo biopsicossocial}

Já na primeira metade do século XIX, complementarmente à tendência biologizante, tivemos um movimento preocupado com uma atenção à tarefa médica e formação do profissional não limitada exclusivamente aos aspectos biológicos. No plano da dimensão social, a partir dos anos quarenta do século XIX, criam-se condições para a emergência da medicina social (Nunes, 2006).

No plano dos aspectos psicológicos, expoentes importantes do movimento de reintegração foram os médicos vienenses Philipp Carl Hartmann e seu discípulo Ernst Freiherr von Feuchtersleben, este último precursor da necessidade do preparo dos médicos em suas aptidões psicológicas.

A perspectiva biopsicossocial, delineada como alternativa ao modelo biomédico, preconiza que a formação do futuro profissional não se restrinja ao campo da biomedicina. Em nosso trabalho de formadores dos profissionais, consideramos essencial uma educação emocional, ética e estética, que demonstre e sensibilize para que, ao lado do preparo para o conhecimento das doenças, ocorra um preparo para o conhecimento das pessoas: que aprender a auscultar as pessoas é tão importante quanto aprender a auscultar um coração; que o ensino de técnicas de comunicação é tão importante quanto o ensino de técnicas cirúrgicas.

Nesta perspectiva, as áreas ligadas às humanidades têm uma contribuição fundamental para a aquisição desses conhecimentos.

\section{A formação do profissional}

Eis alguns pontos que ajudam a evidenciar por que esta formação deve ser considerada essencial para o profissional (Llanes, 2011; Rios, Schraiber, 2011; Grant, 2002; Macnaughton, 2000):

- O conhecimento e o reconhecimento das emoções (em si e no outro) e seu manejo apropriado contribuem, decisivamente, para construir um campo emocional favorável ao desempenho da tarefa médica. Quem já tem experiência neste campo reconhece prontamente a enorme diferença para a relação que advém, por exemplo, da capacidade de continência e empatia, bem como pela observação e manejo da dinâmica transferencial-contratransferencial (De Marco et al., 2012).

- Os dilemas éticos que acompanham desde sempre o exercício da profissão constituem, atualmente, questão altamente crítica (Schraiber, 1997). Hoje, com as intensas mudanças sociais e tecnológicas, a capacitação do profissional neste campo é muito mais necessária e difícil, pois, o campo está em constante transformação. O panorama revela importante defasagem entre, de um lado, as mudanças sociais (que, com a globalização, vêm sofrendo transformações aceleradas e radicais) e as aquisições tecnológicas (com crescimento e transformações exponenciais); e, de outro, as mudanças ético/morais (que, por sua própria natureza, têm gestação e amadurecimento mais lentos).

- Quanto à educação estética, embora à primeira vista possa não parecer tão evidente sua importância para o profissional de saúde, um exame mais atento revela sua grande valia. A arte apresenta, em sua linguagem peculiar, conhecimentos sobre os fatos da vida e das pessoas com profundidade que não pode ser alcançada através de outras linguagens. O contato com a arte 
proporciona transformação no próprio profissional, em sua visão de mundo e qualidade de vida, ao mobilizar "frequências mentais" que favorecem uma visão ampliada do mundo e uma plasticidade desautomatizadora da percepção. A arte é convite à reorganização e experimentação de novas versões do mundo e de si (Tapajós, 2002).

É possível, no curso médico, oferecer o preparo necessário? Certamente não, mas o importante é fornecer referências importantes para que observem, reflitam e para que tenham saídas criativas frente ao inesperado e ao imprevisível, que sempre acontece nos encontros humanos, e deixar claro, parafraseando William Osler (1950), que a educação específica do profissional não é o curso colegial, nem mesmo o curso médico, mas um curso de vida, para o qual o trabalho de poucos anos sob ensino é apenas preparação.

\section{A experiência da Unifesp}

Em nosso trabalho na Unifesp, um cuidado é evitar transformar esse ensino em mera aquisição de técnicas, utilizadas mecanicamente (Rios, Schraiber, 2011).

Entendemos a técnica como recurso útil e necessário a ser incorporado sempre respeitando a equação pessoal e autenticidade. Nesta perspectiva, trabalhamos com diversas técnicas e recursos metodológicos que incluem, no plano formal: trabalhar com pequenos grupos, utilizar diversas técnicas de mobilização psicodramáticas, um laboratório de comunicação no qual utilizamos o recurso de vídeofeedback interativo (De Marco et al., 2010) etc.; e, no plano do conteúdo, o recurso a diferentes fontes de conhecimentos, tanto no campo científico (disciplinas psicológicas, sociológicas, antropológicas etc.) quanto manifestações ligadas à arte, como literatura, teatro e cinema.

No contexto deste trabalho, nos limitamos a apresentar, com mais detalhes, apenas a experiência introdutória que ocorre no segundo semestre do primeiro ano da graduação em medicina.

\section{Conhecendo pessoas - uma ciência, uma arte}

Como introdução a um programa que se estende por todo o curso, utilizamos uma metodologia que incorpora contribuições das ciências e das artes para ampliar o conhecimento do aluno em relação às pessoas e aos dilemas humanos. Textos científicos, contos literários e filmes são estímulos para debates, discussões e planejamento de trabalhos (De Marco et al., 2011; 2009).

A intenção é aguçar a auto-observação e a observação das pessoas, instrumentalizando-as para a flexibilidade necessária para enfrentarem situações, reconhecendo os dilemas humanos e identificando e considerando os aspectos relevantes presentes no campo relacional e comunicacional (o que inclui o reconhecimento de seus estados e sentimentos, bem como os de seus pacientes). Procuramos instrumentalizá-los para reconhecerem e evoluírem suas capacidades de observação, empatia e continência. Para uma efetividade real, procuramos imprimir forte cunho experiencial, através de observação, compartilhamento e reflexão das vivências. Pretendemos, também, que a própria relação professor-aluno sirva como modelo de uma relação viva e autêntica, e o manejo das experiências emocionais ocorra de forma que, estendendo o conceito formulado por Bion, seja promovida a "rêverie do papel profissional", onde as atitudes do professor proporcionem continência, acolhimento e elaboração das vivências, visando favorecer a metabolização de angústias que emergem nas experiências do curso.

"Conhecer pessoas" é o mote do curso que pretende aprofundar o contato dos alunos com diferentes áreas que historicamente têm se interessado pelo conhecimento e equacionamento dos dilemas humanos. As aulas, em pequenos grupos (vinte alunos), visam facilitar o contato entre professores e alunos e favorecer ampla participação.

Através da discussão das contribuições das diferentes áreas de conhecimento, como mitologia, filosofia, psicologia, sociologia, antropologia, história, bem como, produções ligadas à arte, como literatura, teatro e cinema, procuramos sensibilizá-los para o imenso manancial que estas áreas produziram para o conhecimento das pessoas, seus conflitos e dilemas. 
Por exemplo, através da abordagem da psicologia, acessar conhecimentos do desenvolvimento da personalidade, seus momentos críticos, progressões e regressões, demonstrando a ajuda que estes conhecimentos podem proporcionar na detecção de fatores e situações de risco que contribuem para a saúde e a doença, bem como as reações da pessoa frente ao adoecer.

Estes mesmos conhecimentos podem ser muito enriquecidos através de contato com manifestações ligadas à arte.

Assim, se queremos um retrato vivo de como se sente e o que se passa com um doente e seu entorno, bem como uma visão crítica dos médicos e da medicina, a leitura de "A morte de Ivan Illitch" (Tolstoi, 1998) pode ser muito enriquecedora. No texto de psicologia, sociologia, antropologia, vamos encontrar mais informação conceitual; na literatura (nos bons escritores), encontraremos uma visão aguçada da "vida como ela é".

Se quisermos conhecer mais sobre o médico, sua personalidade e as vicissitudes do exercício da medicina, podemos estudar textos (psicológicos, sociológicos, antropológicos), mas se, complementarmente, fizermos uma reflexão sobre o mito de Asclépio e seu tutor Chiron (o curadorferido), com certeza, sairemos bastante enriquecidos.

Por outro lado, se desejamos saber como se sente um médico quando adoece, a leitura do livro "O médico doente", de Dráuzio Varela (2007), nos fornece uma amostra instigante.

Durante o curso, assistimos e discutimos alguns filmes, entre os quais: Freud Além da Alma, Os Quatro Diamantes e Uma Lição de Vida.

O primeiro, desperta interesse dos alunos pela postura investigativa do médico recém-formado Sigmund Freud na busca de entendimento dos quadros histéricos. O filme serve como ilustração para discutir, com os alunos, noções básicas de Psicanálise e sua contribuição para o conhecimento das pessoas.

O filme Os Quatro Diamantes, baseado numa história real, mostra a luta de um menino e sua família com uma doença grave (câncer). O menino Christopher, que costuma fantasiar ser cavaleiro da Távola Redonda, é obrigado, em função da descoberta de um câncer, a fazer uma quimioterapia durante suas férias escolares. Ao retornar às aulas, ao invés da tradicional redação "o que fiz nas férias de verão", é liberado, pelo professor, para escrever uma história de ficção. Envolvendo, em suas fantasias de cavaleiro, médicos e familiares, aborda a luta que trava com sua doença. Este filme sensibiliza muito os alunos, promovendo ampla discussão sobre a comunicação da médica com seu paciente e as diversas reações ao adoecer.

O filme uma Lição de Vida mostra a luta de uma professora universitária, que leciona poesia inglesa, e recebe, através de um oncologista/pesquisador famoso, a notícia de que tem câncer de ovário em estágio avançado. A professora, ela própria, mantinha relacionamento frio e distante com seus alunos e, na posição de paciente, vê-se exposta ao mesmo tratamento que dispensava. O tratamento e evolução de sua doença lhe permitem rever sua vida e sua forma de se relacionar.

O filme propicia a discussão da relação e comunicação médico-paciente, das fases do adoecer, consentimento informado, autonomia e ética em pesquisa.

Na literatura, um texto que temos utilizado é o conto "O Espelho" (1882) de Machado de Assis (Brayner, 1981), autor conhecido pelo olhar minucioso sobre o comportamento humano. Neste conto, o personagem, ao receber um posto militar, é surpreendido pelo respeito e destaque que recebe quando está fardado. Ser visto fardado torna-se necessidade, a ponto de provocar, quando o personagem fica sozinho por breve período, intensa angústia frente a um sentimento de não-existência. O uniforme militar serve como metáfora para se discutir o uso do avental branco, sua interferência nos relacionamentos e o respeito a ele conferido. Numa avaliação do curso, a maioria dos alunos considerou a leitura e discussão deste conto um dos momentos mais marcantes, pela mobilização que produziu para ajudá-los a refletir sobre o papel e as vivências despertadas quando em contato com os pacientes.

Outra atividade marcante é o trabalho final cujo tema é "Conhecendo pessoas: uma ciência, uma arte". O trabalho é proposto no início do curso e os alunos se dividem em grupos (de seis a sete alunos). Eles são estimulados a utilizar recursos tanto da ciência como da arte na formatação do trabalho. A forma e apresentação são muito variadas: montagem de cenas de teatro, produção de filmes, 
entrevistas etc. A experiência promove a aproximação a um campo de conhecimento a partir de uma abordagem pouco habitual para um estudante de medicina, envolvendo importante componente lúdico. Também proporciona oportunidade de exercitar o trabalho em grupo e conhecer melhor seus colegas e a si mesmo.

Este modelo de curso tem indicado que a utilização conjunta de recursos das ciências e das artes tem grande potencial para instrumentalizar vivências e reflexões no futuro profissional, contribuindo para um desenvolvimento pessoal e profissional incorporado, e abertura crítica e aberta frente ao imenso desafio do contato com a condição humana.

\section{Considerações finais: questões e inquietações}

O preparo dos alunos de medicina a partir de conhecimentos que não se enquadram no modelo biomédico pode produzir reações que vão da surpresa à hostilização. As reações podem partir dos próprios estudantes por não entenderem o sentido destes conhecimentos para sua atividade profissional. No plano do ambiente universitário voltado para a área da saúde, trabalhar com este campo coloca o profissional numa situação desprestigiada frente às demandas de valorização e progressão na carreira.

Rees (2010) pontua a questão do que considera as humilhações sofridas pelas pessoas interessadas e dedicadas a promoverem a incorporação de conhecimentos vinculados às humanidades no campo da formação em saúde.

Entre as humilhações mais correntes, está aquela expressa através de formulações, como: "qual a diferença que faz na prática" e, mais especificamente, "qual o custo-benefício?"

Esta questão pode facilmente provocar choque e confusão nos profissionais interessados pelo campo, uma vez que, à primeira vista, parece bastante pertinente, pois, o que é exatamente a medicina senão, de um lado, um conjunto de práticas orientadas para ações voltadas à provisão de serviços considerados benéficos para os receptores, e, de outro, o reembolso desses serviços?

Neste contexto, no qual utilidade e eficiência são os déspotas beneficentes para quem todos respondem, nada mais justo que exigir às humanidades médicas justificarem seu custo (Rees, 2010).

A resposta a esta exigência tem sido, de uma forma geral, a tentativa, por parte dos professores e pesquisadores da área, de demonstrarem o valor de seu trabalho a partir de indicadores como: aumento de satisfação com a experiência, aumento da aderência a tratamentos, comunicação mais efetiva, melhor manejo de sintomas, redução do estresse associado a diagnósticos difíceis, custo-efetividade e redução de custos.

A adesão a estas exigências tem despertado inquietações, expressas em algumas questões, formuladas por Rees (2010), que subscrevemos e deixamos aqui registradas para estimular debate e inquietudes: qual o perigo desta adaptação? Será um alistamento no movimento tecnológico e administrativo para melhorar a eficiência e utilidade da medicina? Uma submissão às agendas da medicina e da ética médica, que trata as humanidades como um refúgio das questões difíceis, ao invés de um cadinho para questões difíceis? Uma contribuição para a progressiva aquisição e refinamento destes fins, e não para provocar questões internas ou que possam ser disruptivas? Ou, finalmente, para melhorar o trabalho dos médicos, e não para questionar esse trabalho e a administração da medicina como uma profissão ética? 


\section{Colaboradores}

Os autores trabalharam juntos em todas as etapas de produção do manuscrito.

\section{Referências}

BION, W.R. O aprender com a experiência. Rio de Janeiro: Imago, 1991.

. Cogitações. Rio de Janeiro: Imago, 1992.

BRAYNER, S. (Org.) O conto de Machado de Assis: antologia. Rio de Janeiro: Civilização Brasileira, 1981.

DE MARCO, M.A. A face humana da Medicina. São Paulo: Casa do Psicólogo, 2003.

DE MARCO, M.A. et al. Psicologia médica: abordagem integral do processo saúde-doença. Porto Alegre: Artmed, 2012.

Conhecendo pessoas - uma ciência, uma arte: breve relato de uma experiência na Graduação Médica da EPM-UNIFESP. Interface (Botucatu), v.15, n.39, p.1219-22, 2011.

. Laboratório de comunicação: ampliando as habilidades do estudante de medicina para a prática da entrevista. Interface (Botucatu), v.14, n.32, p.217-27, 2010.

Semiologia Integrada - uma experiência de aproximação antecipada e

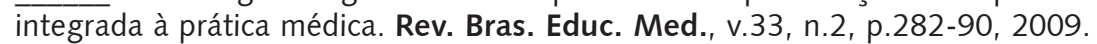

GOMES, R.M.; SCRAIBER, L.B. A dialética humanização-alienação como recurso à compreensão crítica da desumanização das práticas de saúde: alguns elementos conceituais. Interface (Botucatu), v.15, n.37, p.336-50, 2011.

GRANT, V.J. Making room for medical humanities. Med. Human., v.28, n.1, p.45-8, 2002.

HOFFMAN, M.L. Empathy and moral development: implications for caring and justice. New York: Cambridge University Press, 2000.

HUNTER, P. The basis of morality. EMBO Rep., v.11, n.3, p.166-9, 2010. doi:10.1038/ embor.2010.19.

JUNG, C.G. O eu e o inconsciente. Petrópolis: Vozes, 1987.

KESSELRING, T. Ética e emoções morais. Cad. IHU Ideias, v.4, n.52, p.1-15, 2006.

LLANES, M.E.M. Ciencias Sociales y Humanísticas en la formación médica. Rev. Hum. Med., v.11, n.1, p.18-44, 2011.

MACNAUGHTON, J. The humanities in medical education: context, outcomes and structures. Med. Human., v.26, n.1, p.23-30, 2000.

MOLNAR-SZAKACS, I. From actions to empathy and morality: a neural perspective. J. Econ. Behav. Org., v.77, n.1, p.76-85, 2011.

NUNES, E. Saúde coletiva: uma história recente de um passado remoto. In: CAMPOS, G.W.S. et al. (Orgs.). Tratado de saúde coletiva. Rio de Janeiro: Hucitec, Fiocruz, 2006. p.295-315.

OSLER, W. Aphorisms from his bed side teachings and writings. Collected by Robert Bennett Bean; edited by William Bennett Bean. New York: Henry Schuman Inc., 1950.

REES, G. The ethical imperative of medical humanities. J. Med. Humanit., v.31, n.4, p.267-77, 2010.

RIOS, I.C.; SCHRAIBER, L.B. Uma relação delicada: estudo do encontro professor-aluno. Interface (Botucatu), v.15, n.36, p.39-52, 2011. 
SCHRAIBER, L.B. No encontro da técnica com a ética: o exercício de julgar e decidir no cotidiano do trabalho em medicina. Interface (Botucatu), v.1, n.1, p.123-40, 1997.

TAPAJÓS, R. A introdução das artes nos currículos médicos. Interface (Botucatu), v.6, n.10, p.27-36, 2002.

TOLSTOI, L. A morte de Ivan Ilitch. São Paulo: Publifolha, 1998.

VARELLA, D. O médico doente. São Paulo: Companhia das Letras, 2007.

WHITMONT, E.C. A busca do símbolo. São Paulo: Cultrix, 1995.

WINNICOTT, D.W. Da pediatria à psicanálise. Rio de Janeiro: Imago, 2000. 
Neste artigo discutimos os conceitos de humanização e humanidades, sua relação com a comunicação na constituição do sujeito e sua importância na formação profissional, a partir de uma perspectiva do preparo de profissionais que tenham as competências para um trabalho que contemple a integração e a integralidade das práticas. É apresentada uma revisão do campo, discutindo os papéis historicamente atribuídos à natureza e à cultura na constituição do sujeito, particularmente em sua dimensão emocional e moral. É relatado um trabalho que vem sendo desenvolvido há vários anos no campo da graduação em medicina tendo como referencial conclusões que emergem deste estudo. Finaliza-se com uma reflexão crítica deste trabalho.

Palavras-chave: Humanização da assistência. Humanidades médicas. Comunicação em saúde. Educação médica.

\section{Communication, humanities and humanization: technical, ethical, esthetic and emotional education for students and healthcare professionals}

In this paper, we discuss the concepts of humanization and humanities, their relationship with communication in constituting the subject and their importance in professional training, from the perspective of preparing professionals who have the skills for work that includes integration and comprehensiveness of practices. A review of the field is presented, with discussion of the roles historically ascribed to nature and culture in constituting the subject, particularly in its moral and emotional dimensions. We report on a study that has been under development for several years within undergraduate medical education, in which the reference points were the conclusions that emerged from this study. This paper ends by providing critical reflection on this work.

Keywords: Humanization of care. Medical humanities. Health communication. Medical education.

Comunicación, humanidades y humanización: la educación técnica, ética, estética y emocional del estudiante y del profesional de la salud

En este artículo se discute el concepto de humanización y de humanidades, su relación con la comunicación en la constitución del sujeto y su importancia en la formación, desde una perspectiva de la preparación de profesionales con habilidades para un trabajo que incluye la integración y la integralidad de las prácticas .Se presenta una revisión del campo, discutiendo los roles históricamente asignados a la naturaleza y la cultura en la constitución del sujeto, en particular en su dimensión moral y emocional. También se relata un trabajo que se está

desarrollando hace varios años en el campo de la educación médica que tiene como factor referencial las conclusiones que se desprenden de este estudio. Termina con una reflexión crítica de este trabajo.

Palabras clave: Humanización de la atención. Humanidades médicas. Comunicación en salud. Educación médica. 
